\title{
PERBANDINGAN PENDAPATAN PETANI KOPRA JEMUR DAN KOPRA ASAP (STUDI KASUS DESA PASLATEN SATU KECAMATAN TATAPAAN)
}

\author{
Neprianus Siloto \\ Welson M. Wangke \\ Theodora M. Katiandagho
}

\begin{abstract}
ABSRACT
This study aims to see the comparison of income that is located in Paslaten Village between copra clay farmers and dried copra farmers. This research was conducted in March 2016 until August 2016. The data used in this research is using direct interview with 10 (Ten) ie 5 respondents of Copra smoke farmer and 5 respondents of Copra Drying farmers. The data obtained will be tabulated and analyzed in a quantitative and descriptive way. The results of this study indicate the average total income of peanut copra farmers is Rp. 5,371,671.26 in one production, while the average total income of dried coconut copper is Rp. 2,533,740.30 in one production.
\end{abstract}

Keywords: comparison of income, farmers, drying copra, copra smoke

\begin{abstract}
ABSTRAK
Penelitian ini bertujuan untuk melihat perbandingan pendapatan yang bertempat di Desa Paslaten antara petani kopra Asap dan petani Kopra jemur. Penelitian ini dilaksanakan pada bulan Maret 2016 hingga Agustus 2016. Data yang digunakan porposive Sampling Penelitian ini dilakukan dengan teknik wawancara langsung dengan 10 (Sepuluh) yaitu dengan 5 orang responden petani Kopra asap dan 5 responden petani Kopra jemur. Data yang diperoleh akan ditabulasi dan di analisis secara Kuantitatif dan deskriptif. Hasil penelitian ini menunjukkan ratarata total pendapatan petani kopra Asap adalah Rp. 5.371.671,26 dalam satu kali produksi, sedangkan rata-rata total pendapatan petani kopra jemur adalah Rp. 2.533.740,30 dalm satu kali produksi.
\end{abstract}

Kata kunci: perbandingan pendapatan, petani, kopra jemur, kopra asap 


\section{PENDAHULUAN}

\section{Latar Belakang}

Tanaman kelapa (Cocos nucifera L) merupakan tanaman serba guna yang memiliki nilai ekonomi tinggi. Seluruh bagian tanaman mulai dari batang, daun, dan buah, dapat dimanfaatkan untuk pemenuhan kebutuhan manusia, sehingga disebut sebagai pohon kehidupan tree for life (Sutardi, 2008). Tanaman kelapa memiliki potensi keragaman produk yang tinggi karena semua bagian dari tanaman ini bisa dibisniskan mulai dari akar, batang, bunga, buah dan daunnya bisa mendatangkan rupiah bahkan dollar (Suriawira, 2002). Buah kelapa yang terdiri atas sabut, daging buah dan air kelapa, sabut kelapa dapat dibuat menjadi produk industri, antara lain sabut kelapa dapat dibuat keset, sapu, dan matras. Daging buah muda dapat digunakan sebagai bahan pembuat kue dan es. Buah tua dapat digunakan dan di ambil santan, kelapa parutan kering, minyak kelapa, serta kopra. Kopra di proses dengan dua cara yaitu pengasapan dan penjemuran. Adapun tahap pembuatan kopra di awali dengan pemetikan buah, pengangkutan, pengupasan, pembelahan untuk pemisahan daging buah dan terakir pengasapan untk kopra asap, sedangkan kopra jemur dengan penjemuran. Kabupaten Minahasa Selatan merupakan salah satu kabupaten di Provinsi Sulawesi Utara yang merupakan sentra utama tanaman kelapa, dengan luas lahan kelapa seluas 47.810 hektar (ha) dan merupakan lahan kelapa terluas kedua setelah Kabupaten Minahasa Utara yaitu 48.235 ha yang memproduksi kopra di Sulawesi Utara (BPS Sulawesi Utara, 2013). Luasnya potensi pengembangan produk, kemajuan ekonomi perkelapaan ditingkat makro (daya saing dipasar global) maka kegiatan pengembangan kelapa menjadi kopra di Minahasa Selatan merupakan kebutuhan dalam menunjang perekonomian dan kesejahteraan masyarakat, yang mampu menghasilkan devisa bagi negara melalui pengembangan dan dukungan kebijakan pemerintah. Analisis daya saing merupakan alat bantu untuk mengukur daya saing suatu komoditi. Komoditas dengan tingkat stabilitas daya saing yang tinggi memiliki potensi dan kemudahan dalam meningkatkan produktivitas untuk mencapai tingkat daya saing yang lebih baik. Petani di Desa Paslaten Satu kecamatan Tatapaan kabupaten Minahasa Selatan, merupakan salah satu desa penghasil kopra, yang menghasilkan dua jenis kopra yakni kopra asap dan kopra jemur.

\section{Perumusan Masalah}

Proses pembuatan kopra yang berbeda memerlukan waktu dan biaya yang berbeda, yang mengakibatkan pendapatan yang berbeda pula. Permasalahan penelitian ini bagaimana perbedaan pendapatan antara petani kopra asap dan kopra jemur?

\section{Tujuan Penelitian}

Penelitian ini bertujuan untuk membandingkan besarnya pendapatan petani kopra jemur dan kopra asap di Desa Paslaten Satu kecamatan Tatapaan kabupaten Minahasa Selatan.

\section{Manfaat Penelitian}

1. Memberikan informasi kepada petani pendapatan dari kopra Asap dan kopra Jemur di Desa Paslaten satu Kecamatan Tatapaan.

2. Pengambilan Keputusan dalam memberikan rekomendasi pada petani

\section{METODOLOGI PENELITIAN}

\section{Waktu dan Tempat Penelitian}

Peneltian ini dilaksanakan selama 3 bulan yaitu sejak bulan Juni sampai bulan Agustus 2016. Lokasi penelitian adalah Desa Paslaten Satu Kecamatan Tatapaan Kabupaten Minahasa Selatan

\section{Metode Pengumpulan Data}

Penelitian ini menggunakan metode survey, dengan data yang digunakan berupa data primer dan data sekunder. Data primer diperoleh dari responden yakni petani dengan wawancara langsung berdasarkan daftar pertanyaan yang disiapkan dalam bentuk questioner. Sedangkan data sekunder diperoleh dari instansi yang terkait dalam penelitian ini.

\section{Metode Pengambilan Sampel}

Metode pengambilan sampel dengan cara sengaja atau purposive sampling, yakni 
sebanyak 5 petani kopra asap dan 5 petani kopra jemur.

\section{Konsep Pengukuran Variabel}

Variabel yang akan di ukur dalam penelitian ini adalah sebagai berikut :

1. Identitas petani.

2. Jumlah pohon kelapa yang di kelolah.

3. Proses pengolahan buah kelapa.
a. Cara pengolahan
b. Waktu pengolahan

4. Jumlah produksi kopra satu kali proses produksi.

5. Harga kopra per $100 \mathrm{~kg}$.

6. Tenaga kerja yang di gunakan, baik dari dalam keluarga maupun di luar keluarga dan besarnya upah yang di berikan.

7. Peralatan yang di gunakan selama proses produksi serta besarnya sewa alat atau harga alat tersbut.

8. Keuntungan/pendapatan yang di peroleh dari usahatani.

\section{Metode Analisis Data}

Data yang di peroleh di tabulasi dan di analisis secara kuantitatif dan deskriptif.

a. Total Penerimaan (Total Revenue/TR ).

Total penerimaan $=$ harga kopra $\mathrm{x}$ jumlah kopra

$\mathrm{TR}=\mathrm{P} \times \mathrm{Q}$

Dimana:

$\mathrm{P}=$ harga kopra asap/jemur per $100 \mathrm{~kg}$

$\mathrm{Q}=$ jumlah kopra asap/jemur per $100 \mathrm{~kg}$

b. Total Biaya (Total Cost/TC).

Total biaya $=$ Biaya tetap + Biaya variabel

$\mathrm{TC}=\mathrm{FC}+\mathrm{VC}$.

Dimana:

Biaya tetap : sewa lahan/pajak lahan.

Biaya variabel: biaya tenaga kerja, biaya alat,

c. Pendapatan Usahatani.

$$
\text { : biaya transportasi }
$$

Pendapatan Usahatani $=$ Total Penerimaan

$$
=\text { Total Biaya. }
$$

\section{HASIL DAN PEMBAHASAN}

\section{Deskripsi Wilayah Penelitian}

Desa Paslaten Satu merupakan salah satu desa yang ada di Kecamatan Tatapaan Minahasa Selatan. Sebelah Utara berbatasan dengan Kawasan Hutan Lindung, sebelah timur berbatasan dengan Desa Paslaten, sebelah selatan berbatasan dengan Laut Sulawesi, sebelah barat berbatasan dengan Desa Wawona Bajo. Luas Wilayah Desa Paslaten Satu adalah 2315 ha, dengan jumlah penduduk 1010 jiwa. Sebagian besar mata pencaharian penduduk desa Paslaten Satu yaitu berasal dari sektor pertanian, karena sebagian besar lahan di Desa Paslaten Satu merupakan lahan pertanian, termasuk tanaman kelapa.

\section{Karakteristik Responden}

\section{Umur Responden}

Umur mempengaruhi kemampuan seseorang untuk bekerja secara fisik dan dalam pengambilan keputusan. Hasil penelitian menunjukkan bahwa umur ada kaitannya dengan pengalaman seseorang termasuk petani itu sendiri. Petani yang berumur lebih tua cenderung memiliki pengalaman lebih banyak dibandingkan degan petani yang berumur lebih muda. Sedangkan akses terhadap informasi baik petani yang berumur muda dan berumur tua memiliki kemudahan yang sama, sehingga informasi yag diterima tidak tergantung pada umur petani melainkan pada kemajuan teknologi yang dapat dijangkau di Desa Paslaten Satu, salah satunya adalah informasi harga kopra baik di tingkat pedagang pengumpul maupun di industri pengolah kopra.

\begin{tabular}{cccccc}
\multicolumn{2}{l}{ Tabel 1. Umur Responden } \\
\hline \multicolumn{7}{c}{ No } & Umur & $\begin{array}{c}\text { Petani } \\
\text { Kopra } \\
\text { Asap }\end{array}$ & Presentase & $\begin{array}{c}\text { Petani } \\
\text { Kopra Jemur }\end{array}$ & Presentase \\
\hline 1 & $36-50$ & 4 & 80 & 4 & 80 \\
2 & $51-63$ & 1 & 20 & 1 & 20 \\
\hline & Total & 5 & 100 & 5 & 100 \\
\hline
\end{tabular}

Sumber : Diolah dari data primer (2017)

Tabel 1 menunjukan bahwa responden petani kopra jemur dan petani kopra asap paling banyak berada pada umur 36 sampai 50 tahun, berjumlah 8 responden dengan presentase $80 \%$ sedangkan pada umur 51 sampai 63 tahun hanya berjumlah 2 responden dengan jumlah presentase $20 \%$.

\section{Tingkat Pendidikan}

Tingkat pendidikan responden sangat berperan dalam menentukan jenis usaha, pengalokasian input dan semua yang berkaitan 
dengan proses produksi. Tingkat pendidikan responden bervariasi mulai dari SD sampai dengan tingkat pendidikan SMA. Untuk melihat jumlah responden berdasarkan tingkat pendidikan di Desa Paslaten satu Kecamatan Tatapaan dapat dilihat pada Tabel 2.

Tabel 2. Tingkat Pendidikan Responden

\begin{tabular}{|c|c|c|c|c|c|}
\hline \multirow[t]{2}{*}{ No } & \multirow{2}{*}{$\begin{array}{c}\text { Tingkat } \\
\text { Pendidikan }\end{array}$} & \multicolumn{4}{|c|}{ Jumlah Responden } \\
\hline & & $\begin{array}{c}\text { Petani } \\
\text { Kopra } \\
\text { Asap }\end{array}$ & $\begin{array}{c}\text { Presentase } \\
(\%)\end{array}$ & $\begin{array}{l}\text { Petani } \\
\text { Kopra } \\
\text { Jemur }\end{array}$ & $\begin{array}{c}\text { Presentase } \\
(\%)\end{array}$ \\
\hline 1 & SD & 1 & 20 & 1 & 20 \\
\hline 2 & SMP & 2 & 40 & 4 & 80 \\
\hline 3 & SMA & 2 & 40 & - & - \\
\hline & Total & 5 & 100 & 5 & 100 \\
\hline
\end{tabular}

Sumber : Diolah dari data pimer (2017)

Bedasarkan Tabel 2 menunjukan sebagian besar responden berpendidikan SMP dan SMA, dimana untuk responden petani kopra jemur paling banyak berpendidikan SMP berjumlah 4 responden dengan jumlah presentase $80 \%$ dan untuk petani kopra asap yang berpendidikan SMP berjumlah 2 orang dengan jumlah presentase $40 \%$.

\section{Jumlah Tanggungan Dalam Keluarga}

Jumlah tanggungan keluarga merupakan potensi tenaga kerja dalam keluarga, ketersediaan tenaga kerja dalam keluarga sendirinya akan mengurangi pemakaian tenaga kerja dari luar keluarga jumlah tanggungan Keluarga responden dapat dilihat pada Tabel 3.

Tabel 3. Jumlah dan Presentase Responden berdasarkan Jumlah Tanggungan Keluarga

\begin{tabular}{cccccc}
\hline No & $\begin{array}{c}\text { Tanggungan } \\
\text { (Orang) }\end{array}$ & \multicolumn{4}{c}{ Jumlah Responden } \\
\cline { 3 - 6 } & & $\begin{array}{c}\text { Petani } \\
\text { Kopra } \\
\text { Asap }\end{array}$ & $\begin{array}{c}\text { Presentase } \\
(\%)\end{array}$ & $\begin{array}{c}\text { Petani } \\
\text { Kopra } \\
\text { Jemur }\end{array}$ & $\begin{array}{c}\text { Presentase } \\
(\%)\end{array}$ \\
\hline 1 & $1-3$ & 2 & 40 & 2 & 40 \\
2 & $>4$ & 3 & 60 & 3 & 60 \\
\hline & Jumlah & 5 & 100 & 5 & 100 \\
\hline
\end{tabular}

Sumber : Diolah dari data primer, 2017

Tabel 3 menunjukan bahwa tanggungan keluarga responden petani kopra jemur dan petani kopra asap dimana responden petani kopra asap ada 2 responden memiliki tanggungan keluarga antara 1 sampai dengan 3 orang dengan persentase sebesar $40 \%$ dan 3 responden memiliki tanggungan keluarga lebih dari 4 orang dengan persentase sebesar $60 \%$, dan responden petani kopra jemur ada 2 responden memiliki tanggungan keluarga antara 1 dan 3 orang dengan persentase sebesar $40 \%$ dan 3 responden memiliki tanggungan keluarga lebih dari 4 orang dengan persentase sebesar $60 \%$.

\section{Jumlah Pohon Kelapa yang Dikelola Responden}

Perbedaan jumlah pohon kelapa yang dikelola petani akan berpengaruh pada pendapatan petani. Jumlah pohon kelapa mempengaruhi produksi, biaya dan penggunaan tenaga kerja dalam melakukan proses produksi. Jumlah pohon kelapa yang dikelola responden selama proses produksi dapat dilihat pada Tabel 4.

Tabel 4. Jumlah Pohon Kelapa yang Dikelola oleh Petani

\begin{tabular}{ccc}
\hline No Responden & Kopra Asap & Kopra Jemur \\
\hline 1 & 177 & 20 \\
2 & 177 & 71 \\
3 & 204 & 177 \\
4 & 204 & 204 \\
5 & 510 & 612 \\
\hline Total & 1.272 & 1.084 \\
\hline Rata-rata & 254,4 & 216,8 \\
\hline
\end{tabular}

Sumber : Diolah dari data primer, 2017

Tabel 4 menunjukan jumlah pohon kelapa yang dikelola petani pengolah kopra asap antara 177 pohon sampai dengan 504 pohon kelapa, dengan jumlah seluruhnya 1272 pohon kelapa, dan rata-rata pohon kelapa yang dikelola petani sebanyak 254 pohon. Sedangkan responden untuk petani kopra jemur lebih variatif antara 20 pohon sampai dengan 1084 pohon dan rata-rata 216 pohon kelapa yang dikelola.

\section{Biaya Penerimaan dan Pendapatan Petani kopra}

\section{Biaya Produksi}

Biaya tetap petani kopra di Desa Paslaten satu Kecamatan Tatapaan adalah biaya penyusutan alat-alat pertanian. Penyusutan alat merupakan biaya yang perlu dimasukan ke dalam perhitungan biaya tetap. Alat-alat pertanian yang biasa digunakan oleh petani di Desa Paslaten satu seperti lewang, parang, dan kore-kore kelapa, setelah peggunaan alat-alat pertanian beberapa tahun alat-alat pertanian akan mengalami biaya penyusutan. Biaya penyusutan alat-alat pertanian dapat dilihat pada Tabel 5. 
Tabel 5. Biaya Penyusutan Alat-alat Pertanian Kopra Asap dan Kopra Jemur

\begin{tabular}{lcccc}
\hline \multirow{2}{*}{ Uraian } & \multicolumn{2}{c}{ Petani Kopra Asap } & \multicolumn{2}{c}{ Petani Kopra Jemur } \\
\cline { 2 - 5 } & $\begin{array}{c}\text { Jumlah } \\
\text { alat }\end{array}$ & $\begin{array}{c}\text { Jumlah biaya } \\
(\mathrm{Rp})\end{array}$ & $\begin{array}{c}\text { Jumlah } \\
\text { alat }\end{array}$ & $\begin{array}{c}\text { Jumlah biaya } \\
(\mathrm{Rp})\end{array}$ \\
\hline $\begin{array}{l}\text { Biaya } \\
\text { Penyusutan }\end{array}$ & 33 & $170.000,00$ & 25 & $130.000,00$ \\
$\begin{array}{l}\text { Alat } \\
\text { Biaya Rata- } \\
\text { rata/ petani }\end{array}$ & $34.000,00$ & & $26.000,00$ \\
\hline Sumber : Diolah dari data primer, 2017 & & \\
\hline
\end{tabular}

Data pada Tabel 5 menunjukan bahwa untuk biaya penyusutan alat-alat pertanian untuk petani kopra yang ada di Desa Paslaten Satu. Biaya penyusutan alat-alat pertanian petani kopra asap adalah Rp 170.000,00 dengan jumlah alat sebanyak 33 dan rata-rata biaya penyusutan alatalat pertanian dalam satu kali produksi sebesar $\mathrm{Rp}$ 34.000,00 dan biaya penyusutan untuk petani kopra jemur adalah Rp 130.000,00 dengan jumlah alat sebanyak 25 dan rata-rata biaya penyusutan alat-alat pertanian dalam satu kali produksi sebesar Rp 26.000,00. Biaya variabel petani kopra di Desa Paslaten satu meliputih biaya tenaga kerja dan biaya pengangkutan hasil produksi. Biaya variabel petani kopra di Desa Paslaten satu Kecamatan Tatapaan dapat dilihat pada Tabel 6.

Tabel 6. Biaya Varibel Petani Kopra Asap dan Kopra

\begin{tabular}{lcc}
\multicolumn{1}{c}{ Jemur } & & \\
\multicolumn{1}{c}{ Uraian } & $\begin{array}{c}\text { Petani Kopra } \\
\text { Asap }(\mathrm{Rp})\end{array}$ & $\begin{array}{c}\text { Petani Kopra Jemur } \\
(\mathrm{Rp})\end{array}$ \\
\hline Biaya tenaga kerja & $32.490 .000,00$ & $39.611 .000,00$ \\
Biaya & $3.570 .000,00$ & $3.366 .000,00$ \\
pengangkutan & & \\
\hline Total & $36.060 .000,00$ & $42.977 .000,00$ \\
\hline Rata-rata biaya/ha & $7.212 .000,00$ & $8.595 .400,00$ \\
\hline Sumber : Diolah dari data primer, 2017 &
\end{tabular}

Tabel 6 menunjukan bahwa biaya variabel untuk petani kopra asap adalah $\mathrm{Rp} 36.060 .000$ dengan rata-rata biaya per hektar sebesar $\mathrm{Rp}$ 7.212.000,00 dan biaya variabel petani kopra jemur adalah $\mathrm{Rp}$ 42.977.000,00 dengan rata-rata biaya per hektar sebesar Rp 8.595.400,00. Untuk melihat Total biaya produksi petani kopra di Desa Paslaten satu Kecamatan Tatapaan dapat dilihat pada Tabel 7.

Tabel 7. Total Biaya Produksi Petani Kopra Asap Dan Petani Kopra Jemur

\begin{tabular}{ccc}
\hline Jenis biaya & $\begin{array}{c}\text { Petani Kopra Asap } \\
(\mathrm{Rp})\end{array}$ & $\begin{array}{c}\text { Petani Kopra } \\
\text { Jemur(Rp) }\end{array}$ \\
\hline Biaya tetap & $190.000,00$ & $115.000,00$ \\
Biaya variabel & $36.060 .000,00$ & $42.977 .000,00$ \\
\hline Total & $36.250 .000,00$ & $43.092 .000,00$ \\
\hline $\begin{array}{c}\text { Rata-rata } \\
\text { biaya/petani }\end{array}$ & $7.250 .000,00$ & $8.618 .400,00$ \\
\hline Sumber : Diolah dari data primer, 2017 &
\end{tabular}

Tabel 7 menunjukan total biaya produksi petani kopra yang ada di Desa Paslaten satu Kecamatan Tatapaan, yaitu total biaya tetap di tambah dengan total biaya variabel. Total biaya produksi petani kopra asap adalah Rp 36.250.000,00 dengan rata-rata biaya produksi per petani sebesar Rp 7.250.000,00 dan total biaya produksi petani kopra jemur adalah $\mathrm{Rp}$ 43.092.000,00 dengan rata-rata biaya produksi per petani sebesar Rp 8.618.000,00.

\section{Penerimaan Petani Kopra}

Penerimaan petani adalah perkalian antara jumlah produksi yang diperoleh dengan harga jual produk. Jumlah produksi dan penerimaan petani di Desa Paslaten Satu Kecamatan Tatapaan bahwa dalam satu musim panen dapat dilihat pada Tabel 8. Tabel 8 menunjukan jumlah produksi petani kopra asap $5.937 \mathrm{~kg}$ dengan total penerimaan petani kopra asap adalah $\mathrm{Rp} 59.370 .000,00$ dengan rata-rata penerimaan dalam satu kali produksi per petani sebesar Rp 11.874.000,00. Total penerimaan petani kopra jemur adalah $\mathrm{Rp}$ 52.294.000,00 dengan rata-rata penerimaan dalam satu kali produksi per petani sebesar Rp 10.458.800,00.

\section{Pendapatan Petani Kopra}

Pendapatan merupakan selisih antara penerimaan dengan semua biaya atau total biaya produksi. Menurut Sukimo (2002) pendapatan total usahatani (pendapatan bersih) adalah selisih penerimaan total denga biaya total yang dikeluarkan dalam proses produksi, dimana semua input yang dimiliki keluarga dihitung sebagai biaya produksi. Pendapatan petani kopra di Desa Paslaten Satu Kecamatan Tatapaan dapat dilihat pada Tabel 9. Tabel 9 menunjukan total pendapatan petani asap sebesar Rp 23.288.356,38 dengan rata-rata pendapatan per petani sebesar Rp 5.371.671,26 untuk petani kopra jemur total pendapatan sebesar Rp 12.668.701,50 dengan rata-rata pendapatan per petani adalah $\mathrm{Rp} 2.533 .740,30$. Pendapatan petani kopra asap per 100 pohon dalam satu kali produksi sebesar Rp. 2.533.860,00 sedangkan untuk petani kopra jemur sebesar Rp. 1200.824,79. Hal ini menunjukkan bahwa pendapatan petani kopra asap lebih tinggi dibandingkan dengan petani kopra jemur, perbedaan pendapatan ini disebabkan oleh perbedaan struktur biaya dan harga yang diterima petani. 
Tabel 8. Jumlah Produksi dan Penerimaan Petani Kopra Asap Dan Petani Kopra Jemur

\begin{tabular}{|c|c|c|c|}
\hline Uraian & $\begin{array}{c}\text { Petani Kopra Asap } \\
\text { Penerimaan (Rp) }\end{array}$ & & $\begin{array}{l}\text { Jemur } \\
\text { (Rp) }\end{array}$ \\
\hline Jumlah Produksi (kg) & 5.937 & 4.754 & \\
\hline Rata-rata Harga Jual (Rp/100kg) & $59.370 .000,00$ & $1.100 .000,00$ & $52.294 .000,00$ \\
\hline Total & $59.370 .000,00$ & & $52.294 .000,00$ \\
\hline Rata-rata per petani & $11.874 .000,00$ & & $10.458 .800,00$ \\
\hline
\end{tabular}

Sumber : Diolah dari data primer, 2017

Tabel 9. Pendapatan Petani Kopra Asap dan Petani Kopra Jemur

\begin{tabular}{lrr}
\hline Uraian & Petani Kopra Asap (Rp) & Petani Kopra Jemur (Rp) \\
\hline Biaya produksi & $21.643,62$ & $13.698,47$ \\
Penerimaan & $59.370 .000,00$ & $52.294 .000,00$ \\
\hline Pendapatan & $23.288 .356,38$ & $12.668 .701,50$ \\
\hline Rata-rata per petani & $5.371 .671,26$ & $2.533 .740,30$ \\
Rata-rata per 100 pohon & $2.533 .860,00$ & $1.200 .824,79$ \\
\hline Sumber : di olah dari data primer, 2017. & &
\end{tabular}

Sumber : di olah dari data primer, 2017.

\section{KESIMPULAN DAN SARAN}

\section{Kesimpulan}

Dari hasil penelitian ini dapat disimpulkan bahwa pendapatan petani kopra asap dan kopra jemur berbeda, pendapatan petani kopra asap lebih tinggi dibandingkan dengan pendapatan petani kopra jemur

\section{Saran}

Diperlukan perbaikan dan perhatian dari pememrintah dalam pemasaran kopra baik kopra asap maupun kopra jemur dan perlu dilakukan penelitian lebih lanjut agar dapat dianalisa penyebab perbedaan pendapatan secara lebih rinci

\section{DAFTAR PUSTAKA}

Gifelem,C.N. 2016. Perbandingan Pendapatan Usahatani Jagung Manis Dan Jagung Biasa di Desa Tontalete Kecamatan Kema. Skripsi. Universitas Sam Ratulangi. Manado.

Ibrahim, R.B. 2005. Analisis Titik Impas Produk Tepung Kelapa Pada Perusahaan PT. Putera Karangetang Desa Popontolen Kecamatan Tumpaan. Skripsi. Universitas Sam Ratulangi. Manado.
Lumintang,I.M. 2015. Analisis Daya Saing Kopra di Minahasa Selatan. Skripsi. Universitas Sam Ratulangi. Manado.

Nazar M Faizal, 2002. Penolakan Ekspor Kopra Secepatnya diantisipasi.

Pangkero, N. 2003. Profil Usaha Pengolahan Kopra Putih pada PT. MANIMPOROK PERKASA. di Desa Tosuraya Kecamatan Ratahan. Skripsi. Universitas Sam Ratulangi. Manado.

Rauw,L.E. 2014. Perbandingan Keuntungan Usahatani Padi Sawah Dengan Teknik Tanam Pindah Dan Teknik Tanam Benih Langsung di Dumoga Utara kecamatang Bolaang Mongondow. Skripsi. Universitas Sam Ratulangi. Manado.

Soekamto,1999. Upaya Meningkatkan Industri Kelapa, Penebar Swadaya Jakarta.

Soekartawi, 1995. Analisis Usahatani. Universitas Indonesia, Jakarta.

Soetopo, K. 2009. Perbandingan Pendapatan Petani Bunga Kol Penerima dan Bukan Penerima Pengembangan Usaha Agribisnis pedesaan (PUAP) di Desa Kakaskasen dua kecamatan Tomohon Utara. Skipsi. Universitas Sam Ratulangi. Manado. 